\title{
Improving Agriculture Sustainability through Subsidization of Cultured Meat Development
}

\author{
Jamieson Greene, Boston University
} \begin{abstract}
research and development of cultured meat.
\section{Statement of Problem}

Increased human activity bears a toll on the environment causing global temperature rise, increased ocean temperature, acidification, sea-level rise, extreme weather events, and ozone depletion. ${ }^{[1]}$ Fossil fuel emissions sparked by human activity have rapid and perverse effects on the Earth. Immediate and definite action is necessary to preserve the state of the human species and prevent environmental collapse.
\end{abstract}

Abstract: Industrial agriculture threatens the prosperity of modern society. Industrial agriculture, and more specifically the production and slaughter that supports the US meat industry, has perverse consequences including environmental devastation, human health complication, human rights violations, animal rights concerns, among a host of other concerns. The gravity and inefficiency of the current industry are heightened upon consideration of a related concern: food insecurity. These crises are closely interconnected, and a solution must be comprehensive. There is a critical need to remedy these negative externalities and restructure the government's role in the meat industry. I propose that the United States restructure its subsidies to divert funding away from corn and grain, which serve to supplement industrial meat production and invest in the

The meat industry is responsible for a substantial amount of fossil fuel emissions. The industrial production of meat overwhelmingly contributes to the climate crisis and environmental destruction. Food production is responsible for $26 \%$ of global greenhouse gas emissions; agriculture occupies $50 \%$ of habitable land in addition to being responsible for $70 \%$ of global freshwater withdrawals and $78 \%$ of freshwater pollution. ${ }^{[2]}$ Food production is thus intrinsic to the crises of climate change, water stress, pollution, forest devastation, and wildlife extinction.
In addition to an accelerating environmental crisis, the United States faces a converse public health concern of obesity. ${ }^{[3]}$ The prevalence of obesity and overweight individuals has doubled since the 1970s, and meat consumption is linked to an increased risk of obesity, heart disease, type two diabetes, high blood pressure, cancer, and other chronic conditions. ${ }^{[4]}$ Current food production has not adequately ameliorated either crisis, and food insecurity serves as an additional challenge to societal health and well-being.

There is thus a need for a comprehensive solution to the climate and public health crises that are motivated by current industrial agricultural processes. The United States leads in meat consumption and production globally on a per capita basis, exporting over 1.26 million metric tons of beef in 2017 and processing one hundred billion pounds of meat that same year. ${ }^{[5]}$ Growing at an annual rate of $2-3 \%$, this statistic demonstrates the need for immediate action to prevent meat production from aggregating insurmountably. 


\section{Alternatives}

Global food production and consumption are causally connected to the climate crisis and food security. A policy proposal must consider and address both crises; to only address one would overlook their entangled relationship and fail to address global meat consumption which intersects both issues. One proposal which has garnered steam recently is a vegetarian or vegan imperative. This suggestion mandates either a severe limitation or complete elimination of animal products from the US diet. This approach has gained traction because it seemingly directly resolves both crises simultaneously: if the meat industry is completely abolished accordingly its contributions to the climate crisis vanish. Scientific consensus overwhelmingly reveals that meat is not nutritionally essential. The Lyon Diet Heart Study found the adoption of a plant-based diet caused a $73 \%$ decrease in coronary events and a $70 \%$ decrease in mortality among participants. ${ }^{[6]}$ In addition, the Dietary Guidelines Advisory Committee performed two separate literature reviews in 2010 that found plant-based diets to be associated with lower systolic and diastolic blood pressure and reduced risk of cardiovascular disease and mortality respectively. ${ }^{[7]}$

Compared with non-plant-based diets, particularly those rich in red meat, these studies suggest a vegetarian or vegan diet being nutritionally equivalent, or even healthier than the alternative Standard American Diet, characterized by high consumption of processed meats, sweets, and fatty oils. ${ }^{[8]}$ Widespread elimination of meat from the typical US consumer's diet would have profound effects on mitigating fossil fuel emissions, causing marked improvements to the climate crisis. Meat consumption is intrinsically self-destructive; current industrial agriculture practices deplete precious resources and contribute to health complications.

Beyond individual consumption, public health crises arise from the antibiotics introduced to sustain factory farming. Factory farms control over $99 \%$ of the US farming industry, producing the majority of the meat consumed and exported. However, factory farms have a monetary incentive to cycle through as many animals as possible at a minimal cost. To maximize profit, antibiotics get introduced into the equation, which works to combat the unsanitary nature in these crowded quarters. These antibiotics jeopardize public health, as they lead to antibiotic-resistant bacteria which according to the Center for Disease Control and Prevention can contaminate other animal products as well as produce through soil and water contact, leading to human infections. ${ }^{[9]}$ While the severity of these infections ranges, the $\mathrm{CDC}$ warns that resistant bacteria can cause infected people "to be hospitalized and have higher medical expenses, take longer to get well, [or] die from the infection."'[10] Given these concerns for public health, one could suggest the universal adoption of a plant-based diet as it remedies factory farming's toll on individual and public health as well as the climate.

However, this proposition is an insufficient solution. To eliminate the meat industry suggests an inability to restructure the existing organizations and threatens the livelihood of farmers and blue-collar workers who rely on agricultural production. These systems are deeply rooted in the culture and working structure, particularly in rural America; their complete erasure is unfairly discriminatory to these communities. In these highly rural and remote communities, agriculture employs nearly $17 \%$ of the workforce. ${ }^{[1]}$ As this statistic reflects a substantial percentage of 
people's livelihoods, to mandate that these farms shut down without any proposed alternative is narrow-minded and unnecessarily reductive.

Further, it is not likely that everyone will adopt a plant-based diet. Individual autonomy should extend to taste preferences, particularly upon consideration of the fundamental principles of the United States, which emphasize individual freedom and liberties. Although an end to animal suffering and the amelioration of intensive agriculture's toll on the climate crisis prove powerful motivations for such a government mandate, to remove the freedom of choice in appetite contradicts these principles. While individual freedoms may be constrained in the promotion of the public good in several instances, it is not practical to suggest that this power can extend to the consumer's plate. Moreover, there are disparate nutritional and religious considerations that arise on the topic of food in addition to simple gustatory preference which essentially prohibit the successful implementation of a governmental mandate.

\section{Policy Recommendation}

I propose that the United States can alleviate these crises by diverting funding from traditional livestock on consolidated farms to sustainable agricultural practices. In particular, I recommend that the United States invest in researching and realizing the widespread production of cultured meat.

At the systemic level, current conglomerate agriculture has achieved success in part due to its price advantage over more sustainable methods of production, including smaller, family-owned farms. The USDA released a report indicating that direct-to-consumer pasture-raised poultry could run up to $\$ 24.49 / 1$ b. compared to commodity poultry at $\$ 1.73 / 1 \mathrm{~b} .{ }^{[12]}$ The disparity between these figures indicates that consuming exclusively ethically sourced meat is not a feasible reality for most Americans. The privilege to pay upwards of $\$ 24$ for a pound of chicken is a reality of the $1 \%$ and speaks to the sentiment that organic or better-for-you foods are only a luxury for the rich. However, this stark contrast in chicken prices raises questions as to how industrial agriculture can produce at such a minimal cost. Upon further examination, these practices owe much of their success to the subsidies they receive from the US government. In subsidizing the intensive agriculture industry, the government essentially ensures the continuation of their questionable practices which have detrimental health and environmental outcomes. Beginning in the $1950 \mathrm{~s}$, the United States has implemented policies that encourage the consolidation of farms, resulting in the gradual shift from small, family farms and conscientious meat production toward profit-driven factory farming. [13]

Currently, the United States Government disproportionately supports the meat and dairy industry over other food production, allocating \$38 billion every year to subsidize these industries while simultaneously spending less than one percent of that on vegetable and fruit production. ${ }^{[14]}$ The majority of this budget goes to the largest producers of corn, wheat, rice, cotton, and soybeans. ${ }^{[15]}$ Although it may seem positive that this budget is allocated to support the production of grains and legumes, these crops actually serve as feed for animals on factory farms. Per agricultural researchers at the University of Minnesota, animal feed is responsible for a majority of crop production in the United States, accounting for " $67 \%$ of produced calories and $80 \%$ of produced plant protein."[16] 
Moreover, the idea of the critical importance of self-regulation serves as a core tenet to the US economic structure. The argument behind the laissez-faire approach suggests that this distance allows for competition, creating the best products at the best prices for consumers. However, in the case of the meat industry, this mechanism fails. Current policies inordinately support meat produced in factory farms, driving down these prices in the supermarket while failing to account for their negative externalities. Through longstanding subsidy programs, the government supports the endurance of industrial agriculture, continually promoting it to the consumer through perceived discounts at the grocery store. In reality, though, the consumer actually pays substantially more than their simple receipt reflects. The hidden costs of factory-farmed meat manifest in other sectors of the economy such as healthcare costs or climate disruption. Despite believing themselves to save money, on average, Americans pay an additional $\$ 2$ for every $\$ 1$ spent on factoryfarmed animal products when considering the need to offset these outside costs. ${ }^{[17]}$ In the case of factory-farmed versus ethically sourced, the dollar is not the driving force behind success. The true price is hidden from the consumer - through external costs or subsidy programs - encouraging them to unknowingly further support a failing and devastating industry.

The United States should end its targeted subsidies on livestock-specific grains and antibiotics which incentivize farm consolidation and industrial agriculture practices. This expenditure should be reallocated toward researching and producing cultured meat as a sustainable alternative to traditional livestock.

\section{Justification}

Cultured meat presents a unique, innovative solution to this crisis. It solves the dominant problems within the meat industry without forcing individuals to relinquish their right to personal choice.

Cultured meat extracts muscle cells from an anesthetized animal. It then cultivates those cells in a laboratory or at a commercial scale (which we do not yet have) in a bioreactor in a factory, allowing the strands to blanket each other and ultimately create the same meat for a hamburger, without requiring the slaughter of any animal.

Cultured meat has the potential to dramatically decrease the association between climate change and food production, freeing natural resources previously dominated and exhausted by intensive agriculture. Estimates suggest that cultured meat requires 78 to $96 \%$ lower GHG emissions, 99\% lower land use, and 82 to $96 \%$ lower water use than compared to intensive agricultural methods. ${ }^{[18]}$ Although these early predictions might prove optimistic calculations, they regardless indicate a potential dramatic mitigation in the climate crisis. Cultured meat is produced using only muscle cells and the appropriate laboratory settings; at mass scale, this method of production could constitute a drastic reduction in energy, land, and other resources necessary for traditional farming. Additionally, cultured meat can be produced much more quickly than traditional agriculture, which can range anywhere from one to six years in the case of cow maturation. With greater time and labor efficiency, the nutritional cost for cultured meat is superior to factory-farmed.

These environmental benefits extend to address the global food supply. This alternative supports an accelerating global 
population and can be used to help alleviate food insecurity in impoverished and developing nations. Ruminant meat consumption is expected to rise $88 \%$ by 2050 - this cannot be achieved sustainably without a drastic change in current practices. $^{\left[{ }^{19]}\right.}$ Since cultured meat is produced using only cells, it is postulated that a single cow could meet the global demand for meat. ${ }^{[20]}$ A single sample can propagate into over 800 million strands of tissue or 80,000 quarter pounders. ${ }^{[21]}$ In a fraction of the space of traditional livestock, cultured meat efficiently streamlines protein production, serving as a viable solution to the global food crisis. Further, current manufacturing systems are not appropriately set up to account for the rising demand for meat correlating to rapid population growth, particularly in developing countries. Estimates suggest that meat consumption will increase by two-thirds within 40 years. ${ }^{[22]}$ The existing industry is not equipped to meet this growth, potentially driving meat and other staple foods to become an expensive luxury due to disproportionate demand and inherently limited supply. In contrast, with sufficient research, cultured meat could replace traditional farming, reducing greenhouse gas emissions, land space, and ensuring equal opportunity in food consumption.

In comparison to industrial agriculture, cultured meat requires a fraction of the infrastructure. Factory farms use a disproportionate amount of land, energy, and natural resources; the conscious support of cultured meat as an alternative frees up these materials, allowing a more equitable distribution across sectors including smaller, ethical farms, sustainable crop production, and reinforcing lands that have been depleted through overgrazing.
In addition to alleviating the strain on natural resources, cultured meat poses a solution to another public health epidemic: obesity. Factory farmers are incentivized to increase profit at the expense of the wellbeing of the animal, environment, or others. Not only does this system lead to pollution, but it is associated with numerous public health complications. Meat consumption contributes to obesity, which places individuals at risk of life-threatening conditions. Cultured meat can help alleviate this concern. Laboratory growth allows for modifications, offering the potential to create healthier meat by reducing saturated fats and replacing them with omega fatty acids and increased vitamins and nutrients; as noted by Balasubramanian et al. "this designer meat has the advantage of being produced in bioreactors that can be a step up in much less space, and the harvest can be rapidly done with all possible customizable nutrients such as vitamins, proteins, minerals, and add on nutrients as well."[23] Cultured meat in fact triumphs over conventional practices, which must use antibiotics and unnatural processes to stimulate speedier growth of the animal, and instead "requires less time and produces maximum yield, so that one single animal is enough to feed the population."[24] In this way, laboratory-grown meat truly epitomizes the capitalist ideal of the resource investment and market cost. A shift towards cultured meat not only can help create a healthier society but is beneficial from an economic standpoint as it can reduce government expenditures on public health.

In addition to restructuring meat to contain more vitamins and a more controlled fat content, cultured meat resolves the concern of meat contamination that overwhelms slaughterhouses and intensive agriculture. The sanitized laboratory setting minimizes 
the risk of exposure to toxic chemicals. Unlike factory farms, it no longer requires the addition of antibiotics and hormones into meat, the benefits of which transcend cattle health and improve human health by preventing the overabundance of antibioticresistant strains of bacteria and diseases.

Investing in the research and production of cultured meat is essential to provide a comprehensive and accurate solution to these entangled issues. A reality where cultured meat is seen as a viable alternative to traditional livestock is not in that distant of our future. In 2020, Singapore restaurant 1880, partnered with the sustainabilityminded company Eat Just to become the first establishment with cultured meat on its menu after receiving regulatory approval. This approval "involved an iterative and extensive safety review by the Singapore Food Agency (SFA)... [and] during this process, Eat Just complied with SFA's food safety requirements for the assessment of novel foods."[25] This regulatory approval serves as a landmark victory for the future of cultured meat; the introduction of cultured meat onto a traditional restaurant menu reflects positively on the possibility for its widespread acceptance and adoption in the future.

However, without government funding and research, cultured meat will not be able to overcome the barriers to its proliferation. The United States Government must divest from factory farming for the reasons outlined above, particularly upon consideration of the efficacy and viability of cultured meat as an alternative. Despite the superiority of cultured meat to intensive agriculture, it faces substantial challenges before it is likely to replace traditional meat on a commercial level. These obstacles include scientific research into stem cell indefinite proliferation, consumer explanation of the need for cultured meat as well as how it is created, vessel formation bypass, price competitiveness with factoryfarmed meat, a definitively favorable fossil fuel footprint, and consumer acceptance. ${ }^{[26]}$ Ending government subsidies that bolster factory farming will solve many of these problems, however, the need to allocate those investments into researching cultured meat is essential to overcome the remaining concerns. If cultured meat can conquer these roadblocks, it will cement its position as the truly sustainable alternative to not only factory farming but also the plant-based mandate. The current food the production model is not sustainable. It is not equipped to address increased global demand, food insecurity, a deteriorating climate, natural resource exhaustion, or animal and human rights violations. Cultured meat presents an innovative solution to these concerns, which are of utmost significance to future life and prosperity. The United States Government should end its subsidies that strengthen factory farming and invest those resources into the research and development of cultured meat.

\section{Endnotes}

[1] "Climate Change Evidence."

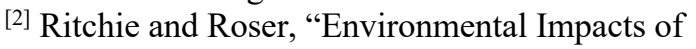
Food Production."

[3] Wang and Beydoun, "Meat Consumption Is

Associated with Obesity and Central Obesity among US Adults."

[4] "Why Obesity Is a Health Problem."

${ }^{[5]}$ Dent, "The Meat Industry Is Unsustainable."

[6-7] Tuso et al., "Nutritional Update for Physicians."

${ }^{[8]}$ Jönsson, "Benevolent Technotopias and Hitherto Unimaginable Meats."

[9] "Where Resistance Spreads: Food Supply."

[10] "Antibiotic Resistance and NARMS

Surveillance."

[11] Ajilore and Willingham, "Redefining Rural America."

[12] "National Monthly Pasture Raised Poultry

Report."

${ }^{[13]}$ Driver, "Industrialization of Agriculture."

[14] Sewell, "Removing the Meat Subsidy." 
[15] "National Monthly Pasture Raised Poultry Report."

${ }^{[16]}$ Cassidy et al., "Redefining Agricultural Yields."

[17] Sewell, "Removing the Meat Subsidy."

[18] Petetin, "Frankenburgers, Risks and Approval."

${ }^{[19]}$ Ranganathan et al., "How to Sustainably Feed 10 Billion People by 2050, in 21 Charts."

${ }^{[20]}$ Bhat and Fayaz, "Prospectus of Cultured MeatAdvancing Meat Alternatives."

[21] "Growing Beef."

[22] Schaefer, "Lab-Grown Meat."

[23-24] Balasubramanian et al., "The Epic of In Vitro

Meat Production-A Fiction into Reality."

[25] "Eat Just Granted World's First Regulatory

Approval for Cultured Meat."

${ }^{[26]}$ Bhat and Fayaz, "Prospectus of Cultured MeatAdvancing Meat Alternatives."

\section{References}

Ajilore, Olugbenga, and Caius Willingham. "Redefining Rural America." Center for American Progress, July 17, 2019.

https:/www.americanprogress.org/article/redefiningrural-america/.

"Antibiotic Resistance and NARMS Surveillance." Centers for Disease Control and Prevention,

November 21, 2019.

https://www.cdc.gov/narms/faq.html.

Balasubramanian, Balamuralikrishnan, Wenchao Liu, Karthika Pushparaj, and Sungkwon Park. "The Epic of In Vitro Meat Production-A Fiction into Reality." Foods 10, no. 6 (June 16, 2021): 1395.

https://doi.org/10.3390/foods 10061395.

Bhat, Zuhaib Fayaz, and Hina Fayaz. "Prospectus of Cultured Meat-Advancing Meat Alternatives."

Journal of Food Science and Technology 48, no. 2 (April 1, 2011): 125-40.

https://doi.org/10.1007/s13197-010-0198-7.

Cassidy, Emily S., Paul C. West, James S. Gerber, and Jonathan A. Foley. "Redefining Agricultural Yields: From Tonnes to People Nourished per Hectare." Environmental Research Letters 8, no. 3 (August 1, 2013): 034015. https://doi.org/10.1088/1748-9326/8/3/034015.

Chriki, Sghaier, and Jean-François Hocquette. "The Myth of Cultured Meat: A Review." Frontiers in Nutrition 7 (2020).

https://www.frontiersin.org/article/10.3389/fnut.2020 .00007 .
Climate Change: Vital Signs of the Planet. "Climate Change Evidence: How Do We Know?" National Aeronautics and Space Administration. Accessed February 21, 2022. https://climate.nasa.gov/evidence.

Dent, Michael. "The Meat Industry Is

Unsustainable.” IDTechEx, March 25, 2020.

https:/www.idtechex.com/en/research-article/themeat-industry-is-unsustainable/20231.

Driver, Kelly. "Industrialization of Agriculture." Johns Hopkins Bloomberg School of Public Health. Accessed February 21, 2022.

http:/www.foodsystemprimer.org/foodproduction/industrialization-of-agriculture/.

Business Wire. "Eat Just Granted World's First Regulatory Approval for Cultured Meat," December 2, 2020.

https:/www.businesswire.com/news/home/20201201 006251/en/Eat-Just-Granted-World\%E2\%80\%99sFirst-Regulatory-Approval-for-Cultured-Meat.

People for the Ethical Treatment of Animals. "Factory Farming: The Industry Behind Meat and Dairy," June 22, 2010.

https://www.peta.org/issues/animals-used-forfood/factory-farming/.

Frank, Adam. "Earth Will Survive. We May Not." The New York Times, June 12, 2018, sec. Opinion. https:/www.nytimes.com/2018/06/12/opinion/earthwill-survive-we-may-not.html.

Mosa Meat. "Growing Beef." Accessed February 21, 2022. https://mosameat.com/growing-beef.

Jönsson, Erik. "Benevolent Technotopias and Hitherto Unimaginable Meats: Tracing the Promises of in Vitro Meat." Social Studies of Science 46, no. 5 (October 2016): 725-48. https://doi.org/10.1177/0306312716658561.

Kateman, Brian. "Will Cultured Meat Soon Be A Common Sight In Supermarkets Across The Globe?" Forbes, February 17, 2020.

https:/www.forbes.com/sites/briankateman/2020/02/ 17/will-cultured-meat-soon-be-a-common-sight-insupermarkets-across-the-globe/.

"National Monthly Pasture Raised Poultry Report." United States Department of Agriculture, n.d. https://www.ams.usda.gov/mnreports/pymnprpoultry. pdf.

Petetin, Ludivine. "Frankenburgers, Risks and Approval." European Journal of Risk Regulation 5, 
no. 2 (June 2014): 168-86.

https://doi.org/10.1017/S1867299X00003585.

Ranganathan, Janet, Richard Waite, Tim Searchinger, and Craig Hanson. "How to Sustainably Feed 10

Billion People by 2050, in 21 Charts." World

Resources Institute, December 5, 2018.

https://www.wri.org/insights/how-sustainably-feed-

10-billion-people-2050-21-charts.

Ritchie, Hannah, and Max Roser. "Environmental Impacts of Food Production." Our World in Data, January 15, 2020.

https://ourworldindata.org/environmental-impacts-offood.

Schaefer, G. Owen. "Lab-Grown Meat." Scientific American, September 14, 2018. https://www.scientificamerican.com/article/labgrown-meat/.

Sewell, Christina. "Removing the Meat Subsidy: Our Cognitive Dissonance Around Animal Agriculture." Journal of International Affairs, February 11, 2020. https://jia.sipa.columbia.edu/removing-meat-subsidyour-cognitive-dissonance-around-animal-agriculture.

"The United States Meat Industry at a Glance." North American Meat Institute. Accessed February 21, 2022.

https://www.meatinstitute.org/index.php?ht=d\%252F sp $\% 252 \mathrm{Fi} \% 252 \mathrm{~F} 47465 \% 252 \mathrm{Fpid} \% 252 \mathrm{~F} 47465$.

Tuso, Philip J, Mohamed H Ismail, Benjamin P Ha, and Carole Bartolotto. "Nutritional Update for Physicians: Plant-Based Diets." The Permanente Journal 17, no. 2 (2013): 61-66. https://doi.org/10.7812/TPP/12-085.

Wang, Y, and MA Beydoun. "Meat Consumption Is Associated with Obesity and Central Obesity among US Adults." International Journal of Obesity (2005) 33, no. 6 (June 2009): 621-28. https://doi.org/10.1038/ijo.2009.45.

Centers for Disease Control and Prevention. "Where Resistance Spreads: Food Supply," November 22, 2021. https://www.cdc.gov/drugresistance/food.html.

"Why Obesity Is a Health Problem." National Heart Lung and Blood Institute, February 13, 2013.

https://www.nhlbi.nih.gov/health/educational/wecan/ healthy-weight-basics/obesity.htm. 